\title{
SIGNIFICAÇÃO DO CONCEITO DE INCLUSÃO ESCOLAR PARA PROFESSORES DE EDUCAÇÃO FÍSICA
}

Robson Frank, Universidade Estadual do Oeste do Paraná - UNIOESTE, Marechal Cândido Rondon, Paraná - Brasil

Luiz Fernando Garcia de Almeida, Universidade Estadual do Oeste do Paraná - UNIOESTE, Marechal Cândido Rondon, Paraná - Brasil

Douglas Roberto Borella, Universidade Estadual do Oeste do Paraná - UNIOESTE, Marechal Cândido Rondon, Paraná-Brasil

Angela Schrone, Universidade Estadual do Oeste do Paraná - UNIOESTE, Marechal Cândido Rondon, Paraná - Brasil

Darlan Boaro, Universidade Estadual do Oeste do Paraná - UNIOESTE, Marechal Cândido Rondon, Paraná - Brasil

Gabriela Simone Harnisch, Universidade Estadual de Campinas - UNICAMP, Campinas, São Paulo-Brasil

\section{RESUMO}

O presente estudo teve por objetivo investigar a significação do conceito de Inclusão Escolar na concepção dos professores de Educação Física dos colégios municipais e estaduais do município de Marechal Cândido Rondon/PR. O estudo caracterizou-se como uma pesquisa de campo, de caráter descritivo, com abordagem quali-quantitativa. A amostra foi de 14 professores, com média de idade de 34 anos. O instrumento para coleta de dados foi um questionário elaborado pelos pesquisadores, com questões abertas. Os resultados encontrados no presente estudo apontaram que quando se trata do entendimento acerca da Inclusão Escolar, 57,2\% dos professores percebem como "inclusão dos alunos com deficiência na turma regular"; $35,7 \%$ a percebem como "igualdade de oportunidades e direitos de participação para todos os alunos"; ao passo que somente um (1) docente relacionou o conceito de Inclusão Escolar com a "inclusão e participação de todos os alunos". Sabe-se que ainda serão necessárias muitas reflexões acerca da Inclusão Escolar, portanto, é imprescindível que além de continuar com pesquisas nesta área, se crie possibilidades de interação entre produção científica e os professores que estão nas escolas.

Palavras-Chave: Inclusão escolar; Educação Física; Educação para todos.

\section{SIGNIFICANCE OF THE CONCEPT OF SCHOOL INCLUSION TO PHYSICAL EDUCATION TEACHERS}

\begin{abstract}
The present study aimed investigating the significance of the concept involving School Inclusion in the Physical Education teacher's conception from colleges of Marechal Cândido Rondon, Paraná State. The study was characterized as a field research and descriptive with qualitative and quantitative approach. Participants were 14 teachers, aged approximately 34 years. The instrument used for data collection was a questionnaire prepared by the researcher with opened questions. The results of this study showed that, when it comes to understanding

Conexões: revista da Faculdade de Educação Física da UNICAMP, Campinas, v. 11, n. 3, p. 86-113, jul./set. 2013.
\end{abstract}


the School Inclusion, 57,2\% of teachers perceive as "inclusion of students with disabilities in regular class"; $35,7 \%$ perceive it as "equal opportunities and participation rights for all students"; while only one (1) teacher related the concept of School Inclusion with the "inclusion and participation of all students". Is already known that are necessary many reflections about the School Inclusion, therefore, is essential that, in addition to continuing with the research in this area, is also important to create possibilities for interaction between scientific contents and the teachers who are working in the schools.

Key-Words: School inclusion, Physical Education, Education for all.

\section{SIGNIFICACIÓN DEL CONCEPTO DE INCLUSIÓN ESCOLAR PARA PROFESORES DE EDUCACIÓN FÍSICA}

\section{RESUMEN}

El presente estudio tuvo como objetivo investigar el significado del concepto de inclusión escolar en el diseño de los profesores de educación física de las escuelas municipales y estatales de Marechal Cândido Rondon / PR. El estudio se caracterizó como una investigación de campo y descriptiva con enfoque cualitativo y cuantitativo. La muestra estuvo conformada por 14 profesores, con una edad media de 34 años. El instrumento de recolección de datos fue un cuestionario elaborado por el investigador, con preguntas abiertas. Por lo tanto, los resultados de este estudio muestran que cuando se trata de la comprensión de la Inclusión Escolar, el 57,2\% de los docentes perciben "como la inclusión de alumnos con discapacidad en las clases regulares"; 35,7\% percibe como "igual los derechos y las oportunidades de participación para todos los estudiantes ", mientras que sólo un (1) los maestros con respecto al concepto de inclusión Escolar con" inclusión y participación de todos los estudiantes ". Sabemos que muchos serán necesarias reflexiones sobre la Inclusión Escolar lo tanto, es esencial que, además de continuar con la investigación en esta área es la creación de posibilidades de interacción entre los científicos y los profesores que están en las escuelas.

Palabras-Clave: Inclusión escolar, Educación Física, Educación para todos. 


\section{INTRODUÇÃO}

Sabe-se da existência das produções teóricas que objetiva falar em diversidade, cidadania, democracia, aceitação da diferença e inclusão social, pois como afirmam Santos e Mendes, ${ }^{1}$ estes são temas bastante em pauta nos últimos anos.

Não obstante, conforme afirma Carvalho, ${ }^{2}$ o conceito de Inclusão Escolar tem sido apresentado por educadores, por outros profissionais ou por pais e familiares, com conotações diferenciadas, e por vezes, contraditórias, o que tem gerado dúvidas e resistências, principalmente dos professores em geral.

Assim, conforme rege a Política de Educação Especial na perspectiva inclusiva, o paradigma da inclusão (neste caso, abordado na temática da Inclusão Escolar) remete-se a questões referentes ao acesso e permanência de todos no ambiente escolar, entendido como uma ação política, cultural, social e pedagógica, desencadeada em defesa do direito de todos os alunos de estarem juntos, aprendendo e participando, sem nenhum tipo de discriminação e preconceito, mas sim de igualdade de direitos ${ }^{3}$.

Neste entendimento, sob enfoque de Caputo e Ferreira, citados por Tremea e Beltrame, ${ }^{4}$ a Educação Física e as demais disciplinas que integram o sistema educacional vêm sofrendo grandes desafios com a inclusão, alterando substancialmente o contexto do ambiente escolar. Os autores referem-se, neste caso, a um problema crucial e presente na realidade escolar: o despreparo dos professores.

Com o intuito de constatar parte desta realidade, os autores supracitados baseiam-se em um trabalho realizado por Tolocka e De Marco, ${ }^{5}$ o qual mostra as implicações da Lei no 9.393/96 para a Educação Física Escolar, apontando, entre os problemas a serem enfrentados, esse tal despreparo por parte dos professores que trabalham com alunos com deficiência.

Pelo presente aqui exposto, entende-se que a Educação Física Escolar envolvendo a integração e a inclusão de todos os alunos implica no direito de todos estarem inclusos, que vale ressaltar, é um direto assegurado por legislações (Constituição Federal do Brasil (1988), Declaração Mundial sobre Educação Para Todos (1990), Estatuto da Criança e do 
Adolescente (1990), Declaração de Salamanca (1994), Política de Educação Especial (1994), na LDBEN 9.394/96 (1996) da Política Nacional de Educação Especial na perspectiva da Educação Inclusiva (2008), entre outros documentos), não deve ser entendido somente como direito do aluno com deficiência, como se tem visto falar nos últimos tempos.

Sob outra ótica, existe a preocupação em relação ao modo como os próprios professores de Educação Física definem conceitualmente a questão da inclusão escolar.3

Neste sentido, cabe-se questionar: como se dá o conceito de inclusão escolar transmitidos pelas vozes de professores de Educação Física? Falar de inclusão escolar é o mesmo que falar de aluno com deficiência incluso?

\section{MÉTODO}

\subsection{Caracterização a Pesquisa}

Para fins deste estudo, optou-se pela realização de uma pesquisa de campo, descritiva, com abordagem quali-quantitativa. De acordo com Thomas, Nelson e Silverman, ${ }^{6}$ quando estas abordagens ocorrem ao mesmo tempo, o delineamento costuma ser chamado de método misto de pesquisa paralela, ou concorrente.

Pesquisa de campo, segundo Marconi e Lakatos, ${ }^{7}$ é aquela utilizada com o objetivo de conseguir informações e/ou conhecimentos acerca de um problema para o qual se procura uma resposta, ou de uma hipótese que se queira comprovar, ou, ainda, descobrir novos fenômenos ou as relações entre eles.

Para Thomas, Nelson e Silverman, ${ }^{6}$ pesquisas descritivas caracterizam-se, frequentemente, como estudos que procuram determinar status, opiniões ou projeções futuras nas respostas obtidas. Neste caso, a pesquisa descritiva tende a mostrar uma realidade momentânea, ou seja, descreve apenas um único momento. As técnicas utilizadas para a obtenção de informações são bastante diversas, destacando-se os questionários, as entrevistas e as observações.

Quanto à abordagem, a pesquisa quantitativa tende a enfatizar a análise (ou seja, separar e examinar os componentes de um fenômeno), enquanto a qualitativa busca compreender o 
significado de uma experiência dos participantes, em um ambiente específico, bem como o modo como os componentes se mesclam para formar o todo. Pode-se dizer que a pesquisa qualitativa enfatiza a "essência" do fenômeno, de momo que o pesquisador não manipula variáveis por meio de tratamentos experimentais, mas interessa-se mais pelo processo do que pelo produto. ${ }^{6}$

\subsection{Instrumento para Coleta de Dados}

Como instrumento para coleta de dados utilizou-se de um questionário com questões abertas referentes ao tema de pesquisa, elaborado pelos pesquisadores.

Conforme Thomas, Nelson e Silverman, ${ }^{6}$ o questionário é um instrumento de coleta de dados que consiste numa tentativa de conseguir informações sobre práticas e condições atuais envolvendo a população do estudo em questão. Deste modo, os autores enfatizam que utilizase um questionário para pedir opiniões ou expressão de conhecimento, sendo a principal justificativa para o uso deste instrumento de coleta de dados, a necessidade de obter respostas das pessoas.

Assim, o referido instrumento de coleta de dados foi composto por questões abertas condizentes ao tema de pesquisa. Optou-se pelas questões abertas por possibilitar aos participantes maior liberdade para expressar suas opiniões.

Ressalta-se que foram feitos testes pilotos para adequação do questionário, a fim de detectar possíveis falhas na sua aplicação. Segundo Thomas, Nelson e Silverman, ${ }^{6}$ o estudo-piloto é essencial para qualquer pesquisa e recomenda-se experiência de campo em local similar ao do estudo proposto. Os autores também enfatizam que além de ir a campo para testar previamente o questionário, é importante detectar possíveis falhas no instrumento que poderiam comprometer a coleta. Destaca-se ainda que os professores que responderem ao questionário-piloto não participaram da pesquisa.

\subsection{Procedimentos para Coleta de Dados}

O procedimento para a coleta de dados realizou-se conforme as seguintes etapas: 
$1^{\text {a }}$ etapa: contato com as diretorias das escolas para apresentação do estudo como também para entrega da carta de apresentação;

$2^{\mathrm{a}}$ etapa: convite aos professores de Educação Física, explanando tanto o tema quanto o objetivo de pesquisa;

$3^{\text {a }}$ etapa: após o convite, foram agendados dias e horários para coleta de dados com os professores participantes e entrega do Termo de Consentimento Livre e Esclarecido;

$4^{\text {a }}$ etapa: coleta de dados in loco. Os participantes só puderam responder as questões na presença do pesquisador, evitando assim possíveis consultas que poderiam atrapalhar ou influenciar na expressão de opinião. Destaca-se também que a coleta foi realizada em horários diferenciados dos horários de aula, pois acredita-se que deste modo, as aulas não sofreriam quaisquer prejuízo em função da pesquisa. Quanto ao local das coletas, todas foram realizadas nas escolas onde os participantes trabalhavam, de acordo com o agendamento, e para cada aplicação de questionário, levaram-se aproximadamente 15 minutos. Vale ressaltar que quando os professores apresentaram dúvidas referentes ao entendimento das questões, o pesquisador acompanhou e explicou novamente o objetivo da questão. Este cuidado foi tomado para evitar respostas incompletas ou fora do contexto da pesquisa. O horário preferido pelos professores foi durante a hora atividade, embora algumas coletas foram realizadas após as aulas. O tempo total de coleta foram de seis (6) dias.

\subsection{Análise dos Dados}

A análise dos dados foi realizada com base nos resultados obtidos por meio das respostas dos professores. Deste modo, os dados foram categorizados, conforme os princípios teóricos de Bardin, ${ }^{8}$ os quais objetivam facilitar a interpretação e discussão das informações obtidas. Assim, a autora coloca que:

a técnica de análise de comunicações visa obter, por procedimentos sistemáticos, a descrição do conteúdo das mensagens que permitam inferência de conhecimentos relativos às condições de produção e recepção 
de mensagens que pertencem ao domínio da análise de conteúdo. Todas as iniciativas, a partir de um conjunto de técnicas parciais, mas complementares, consistam na explicitação e sistematização do conteúdo das mensagens e da expressão deste conteúdo, com o contributo de índices passiveis ou não de quantificação, partem de um conjunto de técnicas, que, embora parciais, são complementares. ${ }^{8: 44}$

Em relação à categorização de dados, Thomas, Nelson e Silverman, ${ }^{6}$ reforçam que trata-se de um aspecto-chave da verdadeira pesquisa qualitativa, pois, em vez de optar pela simples descrição, o pesquisador pode usar dados descritivos como exemplo de conceitos que serão desenvolvidos. Assim, os dados precisam ser estudados e classificados de modo que o pesquisador possa recuperar e analisar as informações por meio da criação de categorias.

Quanto a análise qualitativa, Thomas, Nelson e Silverman ${ }^{6}$ descrevem que é bastante diferente daquela da pesquisa quantitativa, pois em primeiro lugar, na pesquisa qualitativa, a análise é feita durante e após a coleta de dados. Durante a coleta, o pesquisador classifica e organiza os dados, faz especulações e desenvolve hipóteses temporárias, as quais vão orientálo a buscar outras fontes e tipos de dados. Sendo assim, a pesquisa qualitativa é feita de modo semelhante ao da pesquisa de experimentos múltiplos, em que as descobertas feitas durante o estudo definem a forma de cada fase sucessiva desse mesmo estudo. Deste modo, a coleta e a análise de dados simultâneos permitem ao pesquisador trabalhar de maneira mais eficaz com os dados obtidos.

\section{APRESENTAÇÃO E DISCUSSÃO DOS RESULTADOS}

Os dados obtidos neste estudo serão apresentados em forma de quadros e, em seguida, serão discutidos de acordo com as respostas dos professores participantes obtidas por meio do preenchimento do questionário.

Ressalta-se que serão apresentados os dados referentes formação complementar dos participantes, e em seguida, será feita a apresentação e discussão dos dados com relação ao entendimento do tema Inclusão Escolar, de acordo com as questões contidas no instrumento de coleta de dados do presente estudo. 


\subsection{Caracterizando os Participantes}

Faz-se importante ressaltar que os professores serão designados com as letras de "A" a "O" para preservar o anonimato dos participantes.

Participaram da pesquisa 14 professores de Educação Física do município de Marechal Cândido Rondon - PR, atuantes nas redes municipais e estaduais de ensino, sendo seis (6) do gênero masculino e oito (8) do gênero feminino. A idade dos participantes variou entre 20 a 49 anos, sendo a média de 34 anos. Os participantes não precisariam, necessariamente, atuar com alunos com deficiência. Ressalta-se também que os participantes foram selecionados de modo aleatório entre as escolas do município.

\subsection{Análise e Discussão das Questões Referentes ao Entendimento de Inclusão Escolar}

Na sequência, para possibilitar maior liberdade de resposta aos professores participantes, vale destacar que as questões 1, 2, 3 e 4, referentes ao entendimento de Inclusão Escolar foram abertas, nas quais se criaram categorias segundo os princípios teóricos já mencionados. ${ }^{8}$

Deste modo, buscou-se, por meio da análise de conteúdo, tornar as respostas dos professores mais completas, claras e aprofundadas, facilitando assim uma melhor apresentação e discussão de dados.

Inicialmente, a Questão 1 objetivou questionar qual opinião dos docentes em relação ao entendimento de Inclusão Escolar. Afinal, o que os professores pensam quando se fala em Inclusão Escolar?

Para responder a esta questão, apresenta-se primeiramente o Quadro 1, no qual constam já categorizadas e separadas as respostas dos professores. 
Quadro 1 - Opinião dos professores em relação à significação do conceito de inclusão escolar

\begin{tabular}{lcc}
\hline \multicolumn{1}{c}{ Entendimento acerca de inclusão escolar } & FREQUÊNCIA & $\mathbf{( \% )}$ \\
\hline Inclusão e participação de todos na aula & 1 & 7,1 \\
Inclusão do aluno com deficiência na turma regular & 8 & 57 \\
Oferecer oportunidades e direitos iguais de participação & 5 & 36 \\
\hline TOTAL & $\mathbf{1 4}$ & $\mathbf{1 0 0}$ \\
\hline
\end{tabular}

Por meio do Quadro 1, foi possível perceber a opinião dos professores em relação ao conceito de Inclusão Escolar.

Sendo assim, notou-se que apenas um (1) professor relacionou o conceito de Inclusão Escolar com a "inclusão e participação de todos na aula". No entanto, um número mais expressivo respondeu que a Inclusão Escolar está diretamente relacionada com a "inclusão do aluno com deficiência na turma regular", ou seja, demonstrando assim que a inclusão é também um direito dos alunos com algum tipo de deficiência.

A respeito do entendimento acerca do presente contexto, percebe-se que se os docentes não apresentaram experiência suficiente para responder a esta questão, assim, é plausível que surjam dúvidas e dificuldades de compreensão conceitual. Nesta ideia, Carvalho ${ }^{2}$ sugere que as dúvidas podem decorrer, em parte, da insegurança e, também da desconfiança de que hajam outros interesses para a inclusão de alunos com algum tipo de deficiência nas turmas do ensino regular.

$\mathrm{Na}$ sequência, nas respostas dos outros cinco (5) participantes, foram encontrados posicionamentos referentes ao "oferecimento de oportunidades e direitos iguais de participação", o que vale ressaltar que este também não é um conceito equivocado.

Falkenbach, ${ }^{13}$ num estudo referenciado por $\mathrm{Mahl}^{12}$ buscou investigar a prática pedagógica do professor de Educação Física sob o prisma da inclusão. Neste estudo, o autor constatou que é compreensivo os professores não apresentarem conhecimentos sobre inclusão, uma vez que o termo inclusão é recente na área educacional. 
Mesmo sendo esta uma pesquisa de opinião, onde não se julga que se tenha respostas certas ou erradas, pois os professores estiveram livres para expressarem seu entendimento a respeito do tema, encontramos em Omote ${ }^{14}$ que esta realidade apresentada pelo estudo anteriormente referenciado de Falkenbach ${ }^{13}$ pode ser contestada. Mesmo sendo em épocas diferentes, nas palavras de Omote, ${ }^{14}$ a educação inclusiva não implica em nenhuma idéia nova em especial, pois a educação inclusiva não teve início na década passada com a Declaração de Salamanca (1994). Na verdade, as sociedades humanas vêm-se tornando progressivamente inclusivas, há séculos. O resultado disso é universalização dos direitos do cidadão, com inúmeras conquistas por partes das minorias, em diferentes partes do mundo.

Entretanto, acredita-se que para tornar mais claro o entendimento dos conceitos apresentados pelos professores, faz-se necessário transcrever os que se apresentaram mais relevantes para a discussão deste estudo. São eles:

\footnotetext{
"Inclusão Escolar é a possibilidade de uma pessoa com necessidades especiais frequentar uma escola não especializada, ou seja, estudar no Ensino Regular". (Professor "M").

"É a inclusão de alunos com algum grau de deficiência na Escola Regular". (Professor " $N$ ").
}

"Entendo que o aluno com algum tipo de dificuldade de aprendizagem ou deficiência física ou mental possa estar sendo incluso em turmas com alunos 'normais"”. (Professor " $H$ ").

"Inclusão Escolar é dar oportunidade para todos os alunos participarem das aulas, independente da condição de deficiência, ou do tipo de deficiência (física, mental, etc...)". (Professor “C”).

“Inclusão é dar oportunidade a 'todos' de poderem participar da vida escolar regular. Quando escrevo 'todos', são todos que possuem ou não algum tipo de deficiência”. (Professor “ $O$ ”).

"Inclusão é oferecer oportunidades iguais a todos os alunos, respeitando suas limitações, capacidades e habilidades. Considerar que todos tem direito de se desenvolver e participar de maneira igual". (Professor "I").

Conforme verificou-se no Quadro 1, as respostas basearam-se fundamentalmente numa oportunidade de participação e aprendizagem para todos os alunos. Não se pode afirmar que os professores apresentaram conceitos equivocados, uma vez que, como visto anteriormente, nos mais diferenciados conceitos, inclusive no conceito encontrado no site da Secretaria de 
Educação Especial, do $\mathrm{MEC}^{3}{ }^{3}$ os pressupostos da Inclusão Escolar estão intimamente relacionados com a participação e envolvimento de todos no ambiente escolar, onde para todos devem ser oferecidas as mesmas oportunidades, independente da condição de cada aluno.

Concordamos que quando se fala em Inclusão Escolar, não devemos somente pensar no aluno que apresenta alguma deficiência. Ainda que no presente estudo 35,7\% dos docentes, positivamente, relacionaram este conceito com oportunidades e direitos para todos os alunos, notou-se que a maioria, ou seja, 57,2\% ainda entendem que para ocorrer de fato um processo inclusivo, deve-se somente oportunizar que o aluno com deficiência seja inserido na turma regular.

Para Borella, ${ }^{15}$ estas diferenças refletem a constante preocupação de profissionais e pesquisadores em atribuir uma identidade atualizada e devidamente contextualizada à área da Educação Física voltada às pessoas com deficiência. Deste modo, faz-se necessário concordar com Carvalho ${ }^{2}$ quando afirma que ainda tem-se muito a dialogar e a resolver quando o tema é Inclusão Escolar.

A Questão 2 buscou averiguar o posicionamento dos professores perante o processo de Inclusão Escolar, questionando-os se eram a favor ou contra este processo.

Deste modo, o Quadro 2 demonstra-nos a resposta dos professores:

Quadro 2 - Posicionamento dos professores perante o processo de inclusão escolar

\begin{tabular}{lcc}
\hline \multicolumn{1}{c}{ POSICIONAMENTO } & FREQUENCIA & $\mathbf{( \% )}$ \\
\hline A favor & 08 & 57,2 \\
Contra & 03 & 21,4 \\
Depende & 03 & 21,4 \\
\hline TOTAL & $\mathbf{1 4}$ & $\mathbf{1 0 0}$ \\
\hline
\end{tabular}

De acordo com o Quadro 2, nota-se que a maioria dos participantes (08) é a favor deste processo, posicionando-se "a favor" da inclusão escolar, ou seja, favoráveis à participação de todos os alunos - independente da deficiência - em uma aula de Educação Física. Em Conexões: revista da Faculdade de Educação Física da UNICAMP, Campinas, v. 11, n. 3, p. 86-113, jul./set. 2013. 
contrapartida, três (03) professores demonstraram-se "contra", enquanto, outros três (03) posicionaram-se com o entendimento que são favoráveis ao processo de inclusão, desde que haja algumas situações a serem repensadas.

Comparando os resultados com a pesquisa realizada por Mahl, ${ }^{9}$ na qual foram entrevistados seis professores a respeito do mesmo tema, cinco afirmaram serem a favor do processo de inclusão na rede pública de ensino; porém, mencionaram que se faz necessária uma maior reflexão sobre o assunto, pois a ideia de inclusão não remete apenas a "colocar o aluno na escola".

De acordo com a autora citada anteriormente, estas reflexões remetem-se às dimensões físicas e atitudinais que permeiam a área escolar, onde diversos elementos como a arquitetura, engenharia, transporte, acesso, experiências, currículo, conhecimentos, sentimentos, comportamentos, valores, formação especializada, atendimento pedagógico para o aluno, orientação pedagógica para o professor, entre outros estão diretamente relacionadas com as ações vivenciadas nas práticas dos professores. ${ }^{9}$

Os professores que responderam ser a favor do processo de Inclusão Escolar, em sua maioria, justificaram suas respostas enfatizando que todos os alunos têm o mesmo direito de aprender, sem discriminação. As respostas dos professores "C" e "I" evidenciam este posicionamento:

"A favor, pois todos têm o direito de participar das aulas. Na escola é o momento de todos participarem juntos das aulas, num momento de integração". (Professor “C”).

"A favor. O aluno incluso pode aprender como qualquer outro (...) Temos que oferecer as mesmas oportunidades à todos". (Professor "I").

Embora estes professores demonstrassem respostas otimistas, outros mesmo sendo favoráveis ao processo de inclusão, apontaram algumas situações que devem ser repensadas, tais como:

"Sou a favor desde que o professor esteja preparado para atender este aluno e que na sua turma seja respeitado o número limite de alunos ou que se disponibilize um auxiliar para ajuda-lo". (Professor " $H$ ").

"A favor, mas com algumas restrições que vejo observar nas melhorias de infra-estrutura e ou da formação técnica dos professores". (Professor " $G$ ”).

"A favor, se tiver professores capacitados e com conhecimentos das deficiências dos alunos inclusos". (Professor " $D$ ”). 
Com base nestas respostas, percebeu-se que os professores apresentam preocupações tanto com a infraestrutura da escola quanto com a capacitação e preparação por parte dos docentes para poder-se trabalhar com os alunos com algum tipo de deficiência.

Neste sentido, cabe refletir que a proposta de Inclusão Escolar é muito mais abrangente e significativa do que o simples fazer parte (de qualquer aluno), sem assegurar e garantir sua ativa participação em todas as atividades do processo de ensino-aprendizagem, tanto dentro da sala de aula, quanto fora. ${ }^{9}$ Parafraseando a autora, fica evidente que não basta apenas "colocar" os alunos que apresentam alguma dificuldade juntos aos demais sem possibilitá-los que desfrutem de todos os momentos da aula. Vale ressaltar o posicionamento Professores "H”, "G” e "D”, no qual afirmaram que são necessárias algumas mudanças tanto no aspecto físico da escola quanto na formação e capacitação dos professores no sentido de estarem aptos a atender todos os alunos.

Por sua vez, os professores que se posicionaram contra o processo de Inclusão Escolar, utilizaram a justificativa de que além deles próprios não encontrarem-se preparados para realizar um trabalho adequado com os alunos com deficiência, a própria escola muitas vezes não apresenta estrutura e materiais adequados para facilitar este trabalho. Estas afirmações evidenciaram-se nas seguintes respostas:

"No momento, sou contra. As escolas e os professores não estão preparados para atender estes alunos. Eu mesmo, não recebi preparo ou fundamentação durante a graduação". (Professor " $F$ ”).

"Hoje com a pouca experiência que possuo com crianças ou alunos com deficiência, sou contra a escola ter que acolher certos alunos com determinadas deficiência, pois nem a escola (estrutura) nem professores estão preparados para atendê-los adequadamente (diga-se preparados psicologicamente, fisicamente e tecnicamente)". (Professor “O”).

"Hoje sou contra (dependendo muito do grau de comprometimento do aluno). Sei que todos têm direito a frequentar a escola, porém, na prática isso fica comprometido, pois as escolas não têm o espaço físico adequado e os profissionais também não estão preparados para atendelos (...) Em resumo, dependendo do grau de comprometimento, este aluno estará melhor assistido, sem sombra de dúvidas, numa escola especializada". (Professor "M"). 
De acordo com as respostas apresentadas, notou-se uma preocupação por parte dos docentes em relação à insegurança para trabalhar com alunos com alguma deficiência.

Nas palavras de Zulian et al, ${ }^{16}$ a Inclusão Escolar não deve ocorrer de forma indiscriminada. Assim, é necessário preparar o professor para lidar com as dificuldades que poderão surgir nesse processo e para que seja capaz de realizar as adaptações curriculares necessárias. Para isso, os autores destacam que deve ser colocada à disposição do professor, do aluno e da escola, uma rede de materiais e recursos humanos capaz de oferecer suporte às necessidades específicas, auxiliando na manutenção da qualidade de ensino e evitando a segregação do aluno, que poderia resultar da incapacidade do sistema escolar regular de responder às necessidades de seus alunos.

Deste modo, faz-se importante citar Mecca, ${ }^{17}$ quando defende que a Inclusão Escolar não se resume apenas em incluir os corpos dos alunos nas classes regulares, mas sim, quando aos alunos é possível dar as mesmas condições que possui o coletivo, e não mais a individualizando.

E, por sua vez, os professores que não souberam se eram contra ou a favor do processo de inclusão Escolar também apresentaram seu ponto de vista acerca desta questão. As respostas foram as seguintes:

"Depende. Quando o aluno atende aos aspectos sócios educacionais é viável e muito benéfico incluí-lo, fazer ele aprender a conviver com a sociedade e colegas só trará benefícios em todos os aspectos (cognitivo, afetivo, etc). Porém, há casos de alunos que ainda não estão preparados para a inclusão". (Professor " $B$ ").

"Depende do grau de deficiência do aluno". (Professor "J").

"Depende. Às vezes o professor não está preparado ou apto para trabalhar com tal aluno". (Professor " $E$ ").

Por meio das respostas apresentadas, foi possível perceber que os professores relacionaram o processo de Inclusão Escolar tanto com o grau de deficiência do aluno quanto com a própria falta de preparo por parte dos mesmos docentes. Estes fatos possuem fundamental relação com a afirmação de Oliveira e Silva, ${ }^{18}$ na qual os autores enfatizam que o movimento de inclusão está acontecendo, em muitos casos, totalmente à revelia dos professores, os quais na 
maioria das vezes se consideram despreparados para receber alunos com algum tipo de deficiência.

Na Educação Física Escolar, a ideia da Inclusão também divide a opinião dos professores. A relação dos professores de Educação Física com a parcela da população constituída pelas pessoas com deficiência tem se modificado no decorrer dos tempos, conforme Pedrinelli e Verenguer ${ }^{19}$ nos contextualizam. Neste pensamento, é importante levar em consideração que nos próprios institutos de ensino superior em Educação Física, a ideia de programas para pessoas com deficiência tem uma história que data o início nos anos 80. Deste modo, entendese que é totalmente cabível pensar que os professores que se formaram neste período, se não estiverem atualizados com os parâmetros legais envolvendo a Inclusão no contexto escolar, podem apresentar posicionamentos nem sempre favoráveis acerca da Inclusão Escolar.

Na sequência, a Questão 3 teve por objetivo investigar qual o perfil do aluno que deveria estar incluso numa aula de Educação Física, considerando seu contexto prático.

Assim, para demonstrar qual foi a opinião dos docentes sobre esta questão, apresenta-se o Quadro 3:

Quadro 3 - Opinião dos professores em relação ao perfil dos alunos que deveriam estar inclusos nas aulas de Educação Física

\begin{tabular}{lcc}
\hline \multicolumn{1}{c}{ PERFIL DO ALUNO } & FREQUÊNCIA & $(\boldsymbol{\%})$ \\
\hline Todos os alunos & 10 & 71,4 \\
Qualquer aluno com alguma dificuldade & 02 & 14,3 \\
Alunos que não se enquadram no perfil “normal” & 02 & 14,3 \\
\hline TOTAL & $\mathbf{1 4}$ & $\mathbf{1 0 0}$ \\
\hline
\end{tabular}

Com base nestes dados, notou-se positivamente que a maioria dos professores $(71,4 \%$ dos participantes do estudo) concordou que "todos os alunos" devem estar inclusos numa aula de Educação Física, independente da condição de deficiência. Este número apresenta-se com bastante otimismo para o princípio da Inclusão Escolar, que como mencionado anteriormente, envolve a participação de todos os alunos, sem discriminação.

Diante desta realidade, ao se pensar em uma educação sem discriminação, a escola deve assumir o compromisso de educar todos os alunos, de maneira igualitária, valorizando Conexões: revista da Faculdade de Educação Física da UNICAMP, Campinas, v. 11, n. 3, p. 86-113, jul./set. 2013. 
pedagogias que se pautem na diversidade, entendendo assim que todos os alunos deverão estar inseridos na escola regular, independente de sua origem social, étnica ou linguística. ${ }^{20}$

Para tornar mais claro o entendimento da opinião dos professores, a seguir serão transcritas algumas respostas:

"Todos aqueles que convivem bem com os colegas devem ser inclusos nas aulas de Educação Física”. (Professor "B”).

"Todos. O magrinho, o gordinho, o mais e o menos habilidoso, o cadeirante, o quietinho e também o mais agitado". (Professor "I").

"Todos devem estar inclusos. O aluno com inclusão e todos os demais. A aula deve ser para todos e esta aí o grande desafio". (Professor "M").

Vale ressaltar a opinião do Professor "M", o qual percebe a Inclusão Escolar como "um grande desafio".

Quando se pensa numa Educação para Todos como um grande desafio a ser enfrentado, não só pelos docentes como também pela própria comunidade escolar em geral, vale referenciar Ferreira $^{21}$, o qual destaca que estes desafios têm como objetivo possibilitar que todos exerçam o direito a educação em sua plenitude, pois sabe-se que é indispensável que a escola aprimore suas práticas pedagógicas, a fim de atender as diferenças e proporcionar com que todos os alunos aprendam e desfrutem do espaço escolar.

Já os professores que acreditam que os alunos alvos da inclusão é "qualquer aluno com alguma dificuldade” perfizeram um total de dois (02), ou seja, 14,3\% dos participantes. De certo modo, acredita-se que este raciocínio não esteja equivocado, porém, cabe questionar: serão só os alunos com algum tipo de dificuldade que devem ter o direito de participar das aulas?

Ainda, outra parcela de 14,3\% dos professores afirmaram que os "alunos que não se enquadram no perfil "normal" são os alunos que deveriam estar inclusos numa aula de Educação Física. Não diferente do percentual anterior, este raciocínio não está equivocado, porém, novamente cabe questionar: serão somente esses alunos que devem participar das aulas de Educação Física? 
Em ambos os questionamentos percebe-se que os professores mencionaram que os alunos a serem incluídos são aqueles que apresentam alguma dificuldade ou os que não são considerados "normais". Neste sentido, encontramos em Omote ${ }^{14}$ que a maneira como a deficiência ou a dificuldade é concebida e tratada se constitui em uma importante condição para a compreensão do próprio fenômeno das deficiências. O autor enfatiza também que uma limitação ou dificuldade, que pode não ser intrinsicamente determinada pelas características inerentes da pessoa, pode ser tratada como uma deficiência, sendo, portanto, necessário que se tenha em vista a concepção que orienta a pesquisa e as práticas de intervenção, a produção do conhecimento e também sua aplicação. Com base nas afirmações do autor, cabe questionar: não seria este o momento de pensarmos no que se trata "normalidade"? O que é ser normal? Quem é o aluno normal?

Sob outra ótica, vale ressaltar também que não se pode afirmar que os professores opinaram de maneira equivocada, pois de acordo com suas respostas, estes alunos certamente têm o direito de participar das aulas, porém, assim como todos: o com sobrepeso, o menos habilidoso, o mais habilidoso, o menor da turma em tamanho e etc.

Nesta mesma perspectiva, quando indagados sobre como deveria ocorrer o processo de Inclusão Escolar, na Questão 4, os docentes responderam, de acordo com a representação no Quadro 4. Ressalta-se que os docentes puderam opinar livremente conforme a necessidade de completar a resposta. Deste modo, um mesmo docente pôde apontar mais de um procedimento.

Quadro 4 - Opinião dos professores em relação aos procedimentos para efetivar o processo de inclusão escolar

\begin{tabular}{lcc}
\hline $\begin{array}{l}\text { PROCEDIMENTOS PARA EFETIVAR O PROCESSO } \\
\text { DE INCLUSÃO ESCOLAR }\end{array}$ & FREQUÊNCIA & (\%) \\
\hline Adequação atividades e conteúdos & 03 & 17,6 \\
Ter conhecimento sobre Inclusão & 07 & 41,2 \\
Adequação física e material da escola & 05 & 29,4 \\
Respeitar as diferenças dos alunos & 01 & 5,9 \\
Ter acompanhamento particular sobre a deficiência & 01 & 5,9 \\
\hline TOTAL & $\mathbf{1 7}$ & $\mathbf{1 0 0}$ \\
\hline
\end{tabular}

Conexões: revista da Faculdade de Educação Física da UNICAMP, Campinas, v. 11, n. 3, p. 86-113, jul./set. 2013. 
Ficou evidente que ter conhecimento sobre Inclusão foi determinante na opinião dos docentes, sendo o procedimento mais apontado, com 41,2\%. Isso pode indicar que aprofundar o conhecimento a respeito do tema, bem como participar de cursos de capacitação, são determinantes para que ocorra o processo de Inclusão Escolar e, favorecer assim, a participação de todos os alunos não somente na aula de Educação Física, mas também em toda a comunidade escolar.

No que tange à formação inicial e continuada de profissionais da educação, Mahl, Borella e Storch $^{22}$ enfatizam que nas mais distintas áreas profissionais têm suscitado reflexões. Porém, os autores argumentam que estas reflexões estão mais evidentes nos cursos de licenciatura, os quais se tornaram responsáveis por formar professores com elementos teóricos, metodológicos e técnicos indispensáveis para o desenvolvimento de práticas exitosas no ambiente escolar, especialmente sob o advento da inclusão.

Aprofundando-se nestas questões, Borella ${ }^{15}$ acrescenta que a formação inicial constitui um meio para a produção de conhecimento e a Instituição de Ensino Superior (IES) é um lugar que os valores e práticas da educação inclusiva precisam ser vivenciadas objetivando a preparação do profissional de Educação Física ao atuar com pessoas com deficiência, principalmente, porque há um entendimento precípuo de que a futura prática dos docentes egressos dos cursos de Educação Física seja uma condição inerente à sua formação inicial, a qual conseguiu preparar adequadamente os acadêmicos/graduandos para atuar junto às pessoas com deficiência.

Objetivando tornar mais completas e abrangentes as respostas dos professores, na sequência serão transcritas algumas delas:

“O processo de Inclusão Escolar deve ocorrer com muita responsabilidade da parte do professor, que deve buscar sempre conhecer mais sobre o deficiente". (Professor “E”).

"Primeiro: capacitar os professores; depois, analisar a deficiência (seja ela mental ou física) do aluno; em seguida, ser analisada a inclusão por pessoas que já atuaram na área, com conhecimento teórico e prático". (Professor “ $D$ ”). 
"O processo de Inclusão Escolar deve ocorrer de modo gradativo, por meio de informação, além de considerar os espações físicos. Também não se pode 'jogar' os alunos com deficiência com os demais sem um preparo. É preciso ainda bastantes debates, planejamento e conscientização por parte de toda a escola". (Professor "F").

Baseando-se nas respostas acima, entende-se que é de extrema importância manter-se atualizado e isto possui um decisivo enfoque para o professor poder lidar com a Inclusão Escolar. Uma vez inteirado sobre o tema, ele poderá optar por estratégias de ensino que envolva a participação de todos os seus alunos. Já, no entanto, se for "pego de surpresa" sem conhecer sobre o assunto, dificilmente estará preparado para proporcionar um aprendizado a todos.

Diante destes apontamentos, cabe parafrasear Paulon et al., ${ }^{23}$ quando afirmam que a formação dos professores também ganha destaque entre as demandas mais emergentes para o aprofundamento do processo de Inclusão Escolar. Os autores ainda acrescentam que existe um consenso de que é imprescindível uma participação mais qualificada dos educadores para o avanço desta importante reforma educacional.

O "despreparo dos professores", sob a ótica dos autores anteriormente referenciados, figura entre os obstáculos mais citados para a educação inclusiva, o qual tem como efeito o estranhamento do educador com aquele sujeito que não está de acordo com "os padrões de ensino e aprendizagem" da escola. ${ }^{23}$

Outro procedimento citado pelos professores diz respeito à adequação física e material da escola, atingindo um percentual de $29,4 \%$. Notou-se que a preocupação com os recursos físicos e materiais na escola também se constitui num problema a ser solucionado quando se pensa no processo inclusivo e em uma escola para todos.

Confrontando esta realidade, Mahl ${ }^{9: 102}$ sugere que:

as disciplinas dos cursos de Licenciatura em Educação Física, em especial as que tratam do processo de inclusão educacional, poderiam explanar sobre tipologias, patologias, diagnósticos e prognósticos da deficiência, mas acompanhadas de indicações e vivências pedagógicas, contribuindo para que o futuro professor possua um esboço de entendimentos que lhe permita pesquisar, analisar, refletir e executar as melhores ações, estratégias e 
materiais para que o aluno com deficiência realmente efetive sua participação no processo de inclusão nas aulas de Educação Física.

Na sugestão da autora, uma possibilidade para adequar-se as estratégias de ensino e a utilização dos materiais é justamente as disciplinas dos cursos de graduação em Licenciatura oferecerem melhor embasamento teórico e prático para os futuros professores estarem preparados para proporcionar uma aula envolvendo a participação de todos os alunos. ${ }^{9}$

Entretanto, vale ressaltar que a profissão de professor exige imensa versatilidade e capacidade de delinear e desenvolver planos de intervenção em condições muito diferentes e para isso não basta apenas uma formação acadêmica, se faz necessária uma formação profissional continuada, reflexiva e coletiva acerca do processo de inclusão; além de cursos paralelos que mantenham o professor de Educação Física atualizado sobre novas políticas, metodologias, recursos materiais e processos avaliativos frente à inclusão de aluno com deficiência. ${ }^{9}$

Posteriormente, a adequação das atividades e conteúdos também foi apontada pelos docentes, com um percentual de 17,6\%. Embora este não foi um procedimento muito mencionado pelos participantes, entende-se que para ocorrer o processo de inclusão, uma das estratégias é justamente a adequação das atividades e conteúdos por parte do professor, considerando cada turma que ele atua.

Mahl, ${ }^{9: 80}$ referenciando os documentos brasileiros, ${ }^{24-25}$ encontrou conceitos referentes às adaptações e/ou adequações. A autora define que adaptações/adequações significativas do currículo "são pequenas alterações realizadas pelo próprio professor de Educação Física em suas atividades cotidianas", estas relativas à organização de grupos, didática e espaço; aos objetivos, conteúdos e avaliação (adaptações e modificação das técnicas e instrumentos) e, por fim, a temporalidade (modificação do tempo para a aprendizagem dos conteúdos). Já adaptações/adequações significativas "são aquelas que visam à modificação do espaço escolar", propondo uma introdução de conteúdos e objetivos específicos, complementares ou alternativos; adaptação de novos critérios de avaliação e modificação dos critérios; introdução de métodos e procedimentos complementares ou alternativos de ensino e aprendizagem; introdução de recursos ou materiais específicos de acesso ao currículo; temporalidade e 
retenção (quanto tempo os conhecimentos perduram ao longo da escolaridade e o que fazer se o aluno não se apropriar destes conhecimentos).

Neste sentido, alguns autores já vêm, ao longo de suas publicações, enfatizando a preocupação com a adequação das atividades e conteúdos. Podemos encontrar em MauerbergdeCastro $^{26}$ e Oliveira e Profeta ${ }^{27}$ que, em se tratando da concretização da inclusão de alunos com deficiências, o planejamento implica, ainda em uma flexibilidade do currículo. Mesmo que os conteúdos sejam pré-estabelecidos faz-se necessário ajustes para atender as particularidades e especificidades próprias de cada aluno, tornando-o participante do processo ensino e aprendizagem. Estes ajustes são, frequentemente, chamados de adaptações ou adequações curriculares.

Faz-se necessário enfatizar que cada procedimento citado pelos professores, independente do percentual, apresenta sua importância e relevância para o processo de Inclusão Escolar. Não se pode dizer que um é mais certo do que o outro, ou que somente um por si só já é suficiente. Deste modo, cabe considerar todos eles juntos como importantes e indispensáveis ferramentas de inclusão, nas quais todas precisam caminhar de mãos dadas com o intuito de se concretizar a tão "desafiadora" escola para todos.

\section{CONSIDERAÇÕES FINAIS}

Quando se busca respostas para alguns questionamentos, entende-se que anteriormente a estes, existiram alguns problemas ou indagações que muitas vezes nos despertam interesse e curiosidade. No caso do presente estudo, as dúvidas e as questões surgiram em relação a um conceito bastante polêmico e que cria divergências quando se trata de sua complexidade e compreensão do seu significado: a Inclusão Escolar.

Como pode ser percebido no decorrer desta pesquisa, falar em Inclusão Escolar abarca questões que envolvem, em um mesmo momento, toda a comunidade escolar, composta pelos diretores, supervisores, pedagogos e professores; juntamente com quem mais necessita da escola, ou seja, os alunos. Tendo esta concepção, torna-se simples entender que todos os alunos quando vão para a escola, têm o direito de aprender, e a escola, por sua vez, a premissa de ensiná-los. 
Entretanto, se fosse tão simples quanto parece pensar e idealizar uma Escola para Todos, talvez esta pesquisa não tivesse a menor relevância. Podemos encontrar esta realidade em diversas obras, pesquisas, páginas na internet, leis, diretrizes, decretos e em uma infinidade de documentos legais que dizem respeito ao acesso e permanência de todos os alunos no ambiente escolar. Neste sentido, cabe fazer a seguinte questão: se a Inclusão Escolar é garantida por lei, se as escolas possuem condições de receber, e os professores, de trabalhar com todos os alunos, para que ainda se fala nesta questão? Talvez seja necessário que a comunidade escolar entenda que os alunos são diferentes, que aprendem diferente um do outro, que apresentam ritmo de aprendizagem diferente um do outro. Ou seja, cada aluno está inserido num contexto histórico-social diferente e o professor/educador deve respeitar estas diferenças.

Com o intuito de buscar algumas respostas para esta polêmica e abrangente questão que se reconheceu a necessidade da realização deste estudo, mesmo sendo importante ressaltar que, para se compreender tão polêmico tema, seria necessário realizar pesquisas com maior abrangência, envolvendo mais escolas e mais professores, não somente de Educação Física como também os professores das demais disciplinas que compõem as matrizes curriculares.

Em compensação, acredita-se positivamente que os resultados encontrados e as reflexões contidas no decorrer da realização deste estudo representam uma otimista iniciativa em tentar desmistificar os (pré) conceitos teóricos que envolvem uma Educação para Todos.

Deste modo, os resultados encontrados no presente estudo possibilitaram-nos perceber que quando se trata do entendimento acerca da Inclusão Escolar, a maioria dos professores a concebem como inclusão dos alunos com deficiência na turma regular. Conforme já elucidado anteriormente, este não é, totalmente, um conceito errôneo. Porém, permite-se observar que partindo da premissa que a escola deve atender a todos, este conceito parece excluir o restante dos alunos, afinal, são somente os alunos com deficiência que têm o direito de participar das aulas?

Sendo assim, julgou-se imprescindível questionar se os docentes participantes eram a favor ou contra o processo de Inclusão Escolar. Numa perspectiva não tão negativa, percebeu-se que 
nenhum participante foi absolutamente contrário a ideia da Inclusão. Mesmo os que opinaram "contra", fizeram ressalvas em seus discursos enfatizando que para a Inclusão de fato se efetivar, são necessárias mudanças tanto nas escolas quanto em suas próprias práticas pedagógicas. Ou seja, é preciso repensar em meios e iniciativas para que de fato, se possa consolidar a tão comentada Inclusão no ambiente escolar.

Numa ótica mais otimista, pode-se afirmar que a maioria dos professores participantes posicionou-se a favor da Inclusão Escolar, percebendo-a como ótima ferramenta de participação e oportunidade para todos os alunos aprenderem sem discriminação. Ainda vale destacar que, mesmo se tratando de um desafio para os professores, trabalhar com a diversidade faz do professor um profissional mais completo e versátil, capaz de lhe dar com as diferenças dos alunos (e esta diferença não se remete, exclusivamente, aos alunos que apresentam ou não alguma deficiência).

Outro aspecto estudado foi o perfil dos alunos que deveriam estar inclusos numa aula de Educação Física. Com esta questão, buscou-se saber quem os professores entendiam que deviam participar das aulas. Evidenciando outra realidade positiva, a maioria dos professores respondeu que todos os alunos deveriam estar inclusos, sem nenhum tipo de discriminação e sem levar a deficiência em consideração. Ou seja, por meio destas respostas, pode-se inferir que esta maioria dos professores participantes do estudo percebe a Inclusão Escolar como o envolvimento e participação de todos, valendo ressaltar que este é um aspecto característico e presente nos conceitos de Inclusão trazidos ao longo do estudo.

$\mathrm{Na}$ sequência, quando indagados acerca dos procedimentos para efetivar o processo de Inclusão Escolar, os docentes sugeriram diversos meios para que se possa efetivá-la. Entre os quais, o conhecimento acerca da Inclusão foi o procedimento com maior relevância, entendendo-se assim que, este fato pode indicar que o aprofundamento do conhecimento a respeito do tema, bem como participar de cursos de capacitação, são determinantes para que ocorra o processo de Inclusão Escolar e, favorecer assim, a participação de todos os alunos não somente na aula de Educação Física, mas também em toda a comunidade escolar. Outro procedimento que vale ser destacado é a conscientização da formação continuada. Todo 
professor precisa ter consciência que continuar estudando e estar atento aos temas atuais é imprescindível para o exercício da docência.

Por fim, os participantes foram indagados a respeito do conhecimento acerca das leis, diretrizes, decretos e/ou estatutos que dizem respeito ao assunto Inclusão Escolar. De acordo com as respostas, somente quatro professores afirmaram ter conhecimento de alguma lei, diretriz, decreto ou estatuto, mesmo sem se recordar no momento da pesquisa exatamente de qual documento se tratava. Este pode ser um dado preocupante, se pensarmos que a maioria dos professores, mesmo tendo que atender a diversidade em suas aulas, não apresentaram conhecimento das leis e deste modo, não podem se pautar no que dizem os documentos legais em relação à seus direitos e deveres. Entretanto, entende-se que são necessárias mudanças com a premissa de caminharem juntas com as leis, diretrizes, decretos ou estatutos vigentes em nosso país, com o objetivo de oferecer aos professores condições ideais de atender todos os alunos e terem reflexão crítica para formarem um conceito de Inclusão Escolar condizente com cada realidade.

Sabe-se que ainda serão necessárias muitas reflexões acerca da Inclusão Escolar, portanto, é imprescindível que além de continuar com as pesquisas nesta área, se crie possibilidades de interação entre produção científica e os professores que estão nas escolas. Deste modo, acredita-se que os estudos científicos terão maior relevância se forem utilizados como meios de troca de conhecimento entre pesquisadores e professores.

\section{REFERÊNCIAS}

${ }^{1}$ SANTOS, N. A. S.; MENDES, E. G. A inclusão de crianças com necessidades educativas especiais na educação infantil: utopia ou realidade? In: COSTA, M. A. P. R.; DENARI, F. E. (Org.). Educação especial: diversidade de olhares. São Carlos: Compacta, 2006.

${ }^{2}$ CARVALHO, A. R. Inclusão social e as pessoas com deficiência: uma análise na perspectiva crítica. Cascavel, 2009. 180 f. Dissertação (Mestrado em Educação) Universidade Estadual do Oeste do Paraná, Cascavel, 2009. 
${ }^{3}$ BRASIL. Ministério da Educação e Cultura. Secretaria de Educação Especial. Política de educação especial na perspectiva inclusiva Brasília, 2008.

${ }^{4}$ TREMEA, V. S.; BELTRAME, T. S. A criança com síndrome de Down e sua inclusão nas aulas de Educação Física: um estudo de caso. In: RODRIGUES, D.; KREBS, R.; FREITAS, S. N. (Org.). Educação inclusiva e necessidades educacionais especiais. Santa Maria: Ed. da UFSM, 2005.

${ }^{5}$ TOLOCKA, R. E.; DE MARCO, A. A inclusão de pessoas portadoras de necessidades especiais na Educação Física escolar. In: CONGRESSO LATINO-AMERICANO DE EDUCAÇÃO MOTORA, 1, 1998. Foz do Iguaçu. Anais... Foz do Iguaçu: UNICAMP, 1998. p. $265-271$.

${ }^{6}$ THOMAS, J. R.; NELSON, J. K.; SILVERMAN, S. J. Métodos de pesquisa em atividade física. 6. ed. Porto Alegre: Artmed, 2007.

${ }^{7}$ MARCONI, M. A; LAKATOS, E. M. Técnicas de pesquisa: planejamento e execução de pesquisas, amostragem e técnicas de pesquisas, elaboração, análises e interpretação de dados. 5. ed. São Paulo: Atlas, 2002.

${ }^{8}$ BARDIN, L. Análise de conteúdo. 5. ed. Lisboa, Edições 70, 2008.

${ }^{9}$ MAHL, E. Práticas pedagógicas dos professores de Educação Física frente à inclusão de alunos com deficiência. 2012. 153 f. Dissertação (Mestrado em Educação Especial) - Centro de Educação e Ciências Humanas, Universidade Federal de São Carlos, São Carlos, 2012.

${ }^{10}$ SILVA, R. F. Educação Física adaptada no Brasil: da história à inclusão educacional. São Paulo: Phorte, 2008.

${ }^{11}$ RINALDI, I. P. B.; SOUZA, E. P. M. A ginástica como percurso escolar dos ingressantes dos cursos de licenciatura em Educação física da Universidade Estadual de Maringá e da 
Universidade Estadual de Campinas. Revista Brasileira de Ciências do Esporte, Campinas, v. 24, n. 3, 2003.

${ }^{12}$ ARAÓZ, S. M. M.; DENARI, F. E. Deficiência múltipla e Inclusão Escolar: o processo no Brasil. In: DENARI, F. E. (Org.). Igualdade, diversidade e educação (mais) inclusiva. São Carlos: Pedro \& João Editores, 2008.

${ }^{13}$ FALKENBACH, A. P. et al. Inclusão de crianças com necessidades especiais nas aulas de Educação Física na educação infantil. In: FALKENBACH, A. P. (Org.). Inclusão: perspectivas para as áreas da Educação Física, saúde e educação. Jundiaí: Fontoura, 2010.

${ }^{14}$ OMOTE, S. Diversidade, educação e sociedade inclusiva. In: OLIVEIRA, A. A. S.; OMOTE, S.; GIROTTO, C. R. M. (Org.). Inclusão escolar: as contribuições da educação especial. São Paulo: Fundep, 2008.

${ }^{15}$ BORELLA, D. R. Atividade Física Adaptada no contexto das matrizes curriculares dos cursos de Educação Física. 2010. 166f. Tese (Doutorado em Educação Especial) - Centro de Educação e Ciências Humanas, Universidade Federal de São Carlos, São Carlos, 2010.

${ }^{16}$ ZULIAN, M. A. R. et al. A terapia ocupacional em processos interdisciplinares da educação especial. In: OMOTE, S. (Org.). Inclusão: intenção e realidade. Marília: Fundepe, 2004.

${ }^{17}$ MECCA, M. S. Inclusão Escolar: cuidados com as contradições entre a teoria e o que se tem feito na prática. In: DENARI, F. E. (Org.). Educação e educação especial: textos e (con)textos. São Carlos: Pedro \& João, 2012.

${ }^{18}$ OLIVEIRA, A. S. S.; SILVA, N. C. B. Inclusão escolar e formação de professores: a ressignificação da escola e sociedade. In: DENARI, F. E. (Org.). Igualdade, diversidade e uma educação (mais) inclusiva. São Carlos: Pedro \& João Editores, 2008.

${ }^{19}$ PEDRINELLI, V. J.; VERENGUER, R. C. Educação Física Adaptada: Introdução ao universo das possibilidades. In: GORGATTI, M. G.; COSTA, R. F. (Org.) Atividade física 
adaptada: qualidade de vida para pessoas com necessidades especiais. Barueri: Manole, 2008.

${ }^{20}$ LACERDA, C. B. F. O que dizem/sentem alunos participantes de uma experiência de inclusão escolar com aluno surdo. Revista Brasileira de Educação Especial, Marília, v. 13, n. 2, p. 257-280, maio/ago. 2007.

${ }^{21}$ FERREIRA, W. B. Educação inclusiva: Será que sou a favor ou contra uma escola de qualidade para todos? Inclusão: revista da educação especial, Brasília, ano 1, n. 1, p. 40-46 out. 2005 .

${ }^{22}$ MAHL, E.; BORELLA, D. R.; STORCH, J. A. formação inicial em Educação física: prepara-se o futuro professor para avaliar? CONGRESSO REGIONAL DE EDUCAÇÃO FISICA, 4.; ENCONTRO DE PESQUISA EM EDUCAÇÃO FÍSICA, 9. 2010, Marechal Candido Rondon. Anais ... Marechal Cândido Rondon: UNIOESTE, 2010. CD ROM.

${ }^{23}$ PAULON, S. M.; FREITAS, L. B. C.; PINHO, G. S. Documento subsidiário à política de inclusão. Brasília: Ministério da Educação: Secretaria de Educação Especial, 2005.

${ }^{24}$ BRASIL. Ministério da Educação e do Desporto. Parâmetros Curriculares Nacionais: Educação Física: ensino fundamental. Brasília, 1997.

${ }^{25}$ BRASIL. Ministério da Educação e do Desporto. Parâmetros Curriculares Nacionais: Educação Física: ensino médio. Brasília, 1998.

${ }^{26}$ MAUERBERG-deCASTRO, E. Atividade física adaptada. Ribeirão Preto: Tecmed, 2005.

${ }^{27}$ OLIVEIRA, F. I. W.; PROFETA, M. S. Educação inclusiva e alunos com necessidades especiais. In: OLIVEIRA, A. A. S.; OMOTE, S.; GIROTTO, C. R.M. (Org.). Inclusão escolar: as contribuições da educação especial. São Paulo: Fundepe, 2008. 
${ }^{28}$ MAHL, E.; DENARI, F. E. Educação Física e inclusão: quais as efetivas práticas pedagógicas dos professores de Educação Física? CONGRESSO BRASILEIRO DE EDUCAÇÃO ESPECIAL, 3.; ENCONTRO NACIONAL DOS PESQUISADORES EM EDUCAÇÃO ESPECIAL, 4. Anais... São Carlos: EDUFSCar, 2010. CD ROM.

Recebido em: 07 jun. 2013

Aceito em: 03 set. 2013

Contato: Robson Frank

robson_frank_91@hotmail.com 